Thus I conceive that multiplication shou'd be defined from the outset in such a manner as would make it applicable to a fractional as well as to an integral multiplier. If I explain that to multiply 6 by 5 is to repeat 6 five times and find the aggregate result, my explanation fails when I am asked to multiply 6 by $\frac{3}{4}$; but if I use De Morgan's definition that "multiplication consists in doing with the multiplicand what is done with the unit to form the multiplier," or an explanation of multiplication cast in this form, I have given an explanation equally simple with the former and applicable also to a fractional multiplier.

Again, in the very beginning of arithmetic, which is counting I maintain that much would be gained if from the first the child were taught to count, not one, two, \&c., but nought, nothing, or zero, one, two, three, \&c. ; and then if, later on, ordinal reckoning were made to accord with this, though here unfortunately language and usage fails to supply the word wanted, for which, for want of a better, I must coin the form zeroth (noughtth or nothingth being out of the question), thus : zeroth, first, second, \&c. Then the transition to counting below zero by negative numbers would follow at once as by a natural development, when the need for it arose. Thus when it came to the notation of numbers, the place of a digit would properly be reckoned from the units as the zeroth place (not the first), and would be extended naturally by negative ordinal reckoning downwards, when decimal fractions are introduced.

This leads me to another illustration, which I am also anxious to introduce as a suggestion on its own merits. Prof. Chrystal has complained that to many students even when beginning coordinate geometry the idea of the order of a term or an expression is unfamiliar. Now it has occurred to me that this is just the word wanted, to replace the five-syllable word "characteristic," which has been used (or perhaps has not been used just because it is pentasyllabic) to express the distance of any digit of a number in order from the unit's digit. Let us speak of the unit's digit as of the order 0 ; the tens, hundreds, \&c., digits of the orders I, 2, \&c. ; and the tenths, hundredths, \&c., of the orders $-\mathrm{I},-2, \& \mathrm{c}$. ; and add to this that a number is said to be of the same order as that of its highest significant digit, and we have a language not only of the utmost use and importance in decimal arithmetic, but also at once applicable by the most natural extension to an algebraical expression arranged according to the powers of some letter or letters, while it would enable us conveniently to express in language numbers which transcend our ordinary numerical vocabulary, so that, for instance, $53 \times \mathrm{IO}^{12}$ might be read as 53 of the $\mathrm{I} 2 \mathrm{th}$ order, and $53 \times 10^{-12}$ as 53 of the - I th order, and so on.

In conclusion I will only add that, if in this paper $I$ have in any parts expressed myself somewhat dogmatically, I have done so in the hope of challenging discussion, and only claim the acceptance of the views which I have tried to express distinctly, if briffly, in the event of discussion resulting in a verdict in their favour.

\section{ON THE METHOD OF STATING RESULTS OF WATER ANALYSES}

T'HE Chemical Society of Washington is desirous of bringing before chemists and others interested, the report of Com mittee herewith inclosed; and as NATURE has a wide circulation in this country, I am authorised to send a copy of the abstract to your journal, hoping you may find space for it.

$$
\text { A. C. Peale, M.D., }
$$

Sec. Chem. Soc. Washington (Office of U.S. Geol. Survey)

Washington, D.C., February 25

The Chemical Society of Washington, at the meeting of November 12, 1885, appointed a Committee to consider the present state of water analysis, and to present a method of stating analyses, adapted for general use, in order that those hereafter published may be readily compared with each other and with future work. This Committee reported February II, I 886, and was authorised to prepare an abstract for publication, in order to call the attention of chemists to the subject. 'The Society earnestly recommends the adoption of the scheme which is herewith briefly presented. The full text of the report will be published in the next Bulletin of the Society.

\title{
(Abstract)
}

Water analyses are usually made to answer one of three questions, viz :-

(I) Is the water useful medicinally?

(2) Is it injurious to health? and

(3) Is it suitable for manufacturing purposes?

Many books relating to water were published during the eighteenth century, but accurate chemical analysis was not at tempted until about 1820 . As the earlier analyses were isolated, rare, and made for special purposes, the form of the statement was of little importance if it were only intelligible. At the present time, however, water-analyses are very numerous. An examination of about a thousand shows some forty two methods of stating quantitative results, there being sometimes three different ratios in the report of one analysis. Such discrepancies render comparisons difficult and laborious. The various methods of statement may be classified under the following general forms :-

(I) Grains per imperial gallon of 1o lbs. or 70,000 grains.

(2) Grains per U.S. or wine gallon of $58,372+$ grains.

(3) Decimally, as parts per IOO, I000, IOO, 000, or I,000,000.

(4) As so many grammes or milligrammes per litre.

The last two would be identical if all waters had the same density; but as the densities of sea water, mineral waters, \&c., are much above that of pure water, it is plain that the third and fourth modes are not comparable. The Committee therefore unanimously recommends-

(I) That water-analyses be uniformly reported according to the decimal system, in parts per million or milligrames per kilogramme, with the temperature stated, and that Clark's scale of degrees of hardness and all other systems be abandoned.

(2) That all analyses be stated in terms of the radicals found.

(3) That the constituent radicals be arranged in the order of the usual electro chemical series, the positive radicals first.

(4) That the combination deemed most probable by the chemist should be stated in symbols, as well as by name.

The abandonment of Clark's scale has been recommended by Wanklyn and Chapman; and the recommendation made by the Committee does not involve the disuse of his method, but merely the bringing it into accord with the decimal system-the changing from grains per gallon to milligrammes per kilogramme.

The last conclusion (4) was deemed desirable from the frequent confusion in the statement of the iron salts and of the carbon oxides.

The Committee is unanimously of the opinion that analyses in the form recommended will prove quite as acceptable to Boards of Health and to the public in general, for whom such analyses are often made, as if presented in the mixed and irregular forms commonly adopted.

The Committee also feels sure that the people in general are better able to form a definite idea of the character of a water from a report stated in parts per 100, parts per $1,000,000, \&$ c., than from one expressed as grains per gallon, the latter being a ratio wholly unfamiliar to any but those in the medical or pharmaceutical professions.

$$
\text { (Signed) }
$$

A. C. Peale, M.D.

WM. H. SEAMAN, M.D.

Chas. H. White, M.D.

\section{ON SOME POINTS IN THE PHYLOGENY OF} THE TUNICATA

$\mathrm{I} \mathrm{N}$ his monograph on the genus Doliolum, forming one of the recent parts of the series illustrating the Fauna and Flora of the Bay of Naples, ${ }^{1}$ Dr. B. Uljanin gives a sketch of the phylogeny of the Tunicata, some parts of which cannot, I think, be accepted without considerable modification. Uljanin has evidently regarded the subject from the Doliolum point of view, and, in fact, he only introduces the other groups of Tunicata for the purpose of discussing their relationships to Doliolum. Consequently it is not to be wondered at that he should assign rather too central a position to that genus, and give it too much importance relatively to the other groups. What is of more importance is that his scheme shows a course of evolution which seems not altogether in accordance with

I "Fauna und Flora des Golfes von Neapel." Doliolum, von Dr. Basilius Uljanin. (Leipzig, I884.) 